\title{
Combo technique of mandibular anterior ridge defect rehabilitation- Andrews bridge and soft liner
}

\author{
Vikram Panghal ${ }^{1, *}$, Sangeeta Sunda ${ }^{2}$ \\ ${ }^{1}$ Dental Surgeon, ${ }^{2}$ Reader, Dept. of Orthodontics, ${ }^{1}$ Civil Hospital Hisar, Haryana, ${ }^{2} \mathrm{JCD}$ Dental College, Sirsa, Haryana, India
}

*Corresponding Author:

Email: vikrampanghal1981@gmail.com

\begin{abstract}
The loss of teeth invariably is followed by the loss of soft tissue. This article elaborates the process of Andrews bridge fabrication for missing 31,32,33,41,42,43 with natural teeth as abutments for its fixed component and a soft liner based removable component. There are many recent advances in aesthetic dentistry techniques and materials, still certain cases remain difficult to restore. Main advantage of an Andrews's bridge over fixed prosthesis is that it can be removed by the patient for improved oral hygiene access.
\end{abstract}

Keywords: Ridge, Andrews bridge, Abutments, Removable, Soft liner.

\section{Introduction}

Loss of teeth is a natural sequel of aging process. Reasons of tooth loss are extraction, trauma, caries and surgical excision of tumor etc. Loss of tooth results in alveolar process loss and this loss depends on severity of the cause.

Economically removable partial denture is the choice of many dentists for replacing several missing teeth as both aesthetics and required functions are restored. Most of the patients these days want fixed prosthesis for better aesthetics and functions. Prosthodontics relates to diagnosis, treatment plan, maintenance and rehabilitation of oral functions, health, appearance and comfort of patient by using biocompatible substitutes in relation to maxillofacial tissues along with missing teeth. Fixed prosthesis has certain drawbacks especially in long span where teeth are periodontically compromised with some defects in edentulous region. It will be wise to make a treatment plan of removable-fixed partial denture combination.

Removable-Fixed partial denture concept was introduced by Dr. James Andrews. He incorporated a fixed component on the teeth, which were used as abutments, along with removable pontics. On one hand Porcelain Fused to Metal crowns were joined together by casting bar and on another hand removable partial denture with acrylic teeth was fitted on that bar with a soft liner as a base. Andrews Bridge system has an advantage of being used for several missing teeth along with defect in edentulous ridge. Another advantage is of minimum extension of removable partial denture along with better stability and retention.

Esthetics, comfort, phonetics, hygiene are the four reasons which made evolution of Andrews Bridge design concept.

\section{Case Report}

The reason for visit of a fourty nine year old patient to the clinic was unaesthetic appearance due to missing anterior 31,32,33,41,42,43 teeth. Clinical examination reviewed that there was loss of residual ridge. (Fig. 1)

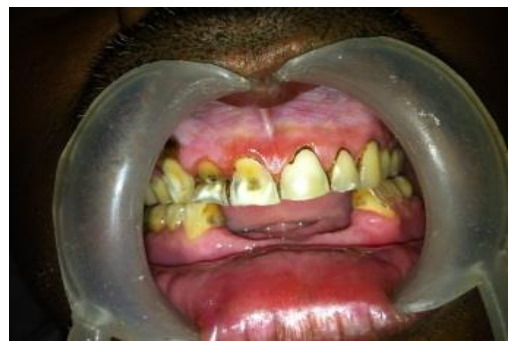

Fig. 1: Pre operative view

Hence treatment plan was made to construct Andrews bridge with soft liner prosthesis. Informed written consent was taken from the patient with advantages and disadvantages being explained regarding the treatment. Mandibular abutment teeth preparation was done creating a shoulder margin supragingival. (Fig. 2)

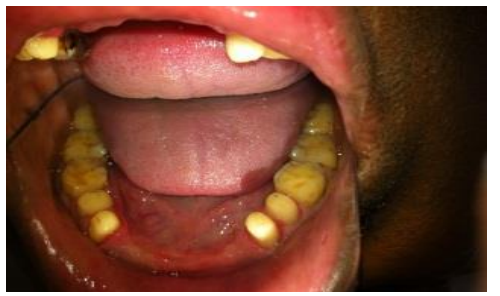

Fig. 2: Tooth preperation irt 34354445

Gingival retraction cord was used for gingival retraction and a full arch impression was made with polyvinyl siloxane impression material for accurate recording of finish line and definitive cast with type IV stone was poured.

According to curvature of the ridge a preformed plastic bar attached with the abutments was then casted in cobalt chromium alloy. 
Try-in of metal framework was done in the patients mouth and clearance was checked between underlying soft tissues and the bar attachment. (Fig. 3)

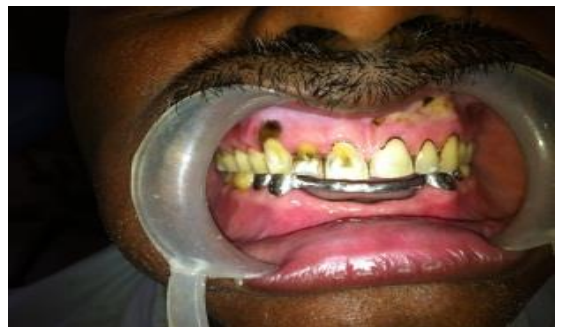

Fig. 3: Copying trial along with the mettalic bar

Once the satisfactory trail of metal frameworkwas done, ceramic layering of metal copings was done with definitive shade selection. Porcelain fused to metal crown cementation was done in relation to $34,35,44,45$. (Fig. 4) Ceramic crowns were placed and occlusion verified. Occlusal rim were placed on the bar attachment and occlusal verification was done with teeth in position.

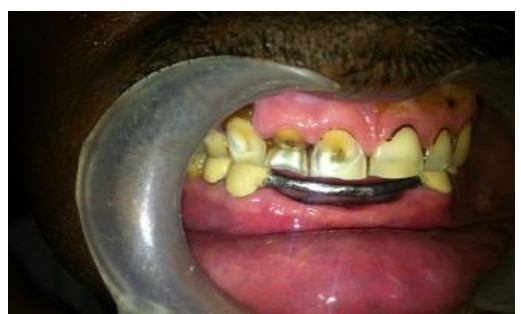

Fig. 4: PFM crown cementation irt 34354445

Occlusal rim was replaced with pink colored heat cured acrylic resin lined by soft liner to fit removable partial denture over the bar attachment. (Fig. 5)

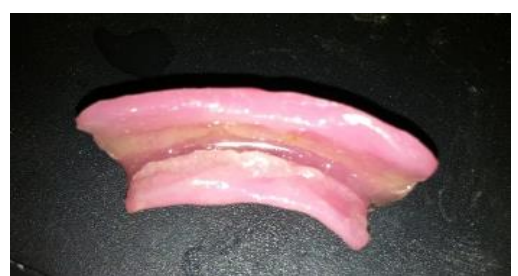

Fig. 5: Prosthesis with soft liner

Bar attachment with ceramic crowns was cemented on the abutment teeth with glass ionomer cement and finally removable prosthesis was fit on the attachment. (Fig. 6) It was made sure that the patient should follow proper oral hygiene instructions with a guidance to remove and insert the removable prosthesis. Evaluation of the attachment was done over a period of one year with interval of 4 months Patient was found happy with the final outcome.

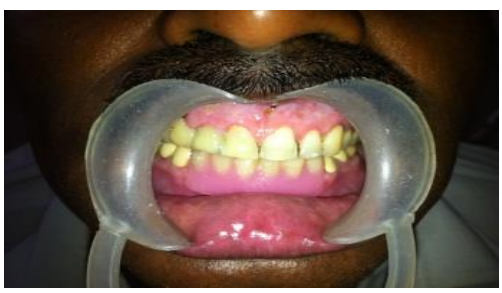

Fig. 6: Post operative view

\section{Discussion}

Maintenance and restoration is the basic need of prosthetic dentistry. Comfort, appearance, oral functions and health of the patient are the areas of concern if replacement of the missing teeth and contiguous tissues is done with artificial substitutes.

Andrews bridge system has a main advantage of having a removable part which can be removed and inserted by the patient making abutments and surrounding structures hygienic. The acrylic segment can be used as many times as patient wants without loosing retention. Failure of such prosthesis is less as found in the literatures. ${ }^{5}$ Single casting of attachments with retainers eliminated the failure of inadequate soldering. Basically Andrews Bridge system has two advantages-

1. Advantage of being used for several missing teeth along with defect in edentulous ridge.

2. Another advantage is of minimum extension of removable partial denture along with better stability and retention

\section{Summary}

Favorable stress distribution to the abutments and soft tissue is the prime concern of Andrews Bridge concept as the defects corrected surgically using implants or grafts are an expensive treatment plan for some patients. Andrews Bridge system has an advantage of being used for several missing teeth along with defect in edentulous ridge.

This challenging situation has a unique alternate of Andrews bridge where not only the teeth are replaced but the supporting structures necessary for aestheticsare also kept in consideration. The main advantage of Andrews bridge is that has an attachment of a fixed bar with removable dental prosthesis that replaces teeth within the bar area.

\section{References}

1. Seibert JS. Reconstruction of deformed, partially edentulous ridges, using full thickness onlay grafts. Part I. Technique and wound healing. Compend Contin Educ Dent. 1983;4(5):437-53. [PubMed]

2. Studer S, Naef R, Scharer P. Adjustment of localized alveolar ridge defects by soft tissue transplantation improves mucogingival esthetics: A proposal for clinical classification and evaluation of procedures. Quintessence Int. 1997;28(12):785-805. [PubMed]

3. Gates GN, Boch AJ. Boulder. Prosthodontics-crown and bridges.mht. 
4. Abrams H, Kopczyk RA, Kaplan AL. Incidence of anterior ridge deformities in partial edentulous patients. $\mathrm{J}$ Prosthet Dent. 1987;57(2):191-94. [PubMed]

5. Garber DA, Rosenberg ES. The edentulous ridge infixed prosthodontics. Compend Contin Edu. 1981;2(4):212 -23. [PubMed]

6. Kaurani, et al. Prosthodontic Rehabilitation of a Case with An Anterior Ridge Defect using Andrews Bridge. Indian Journal of Dental Sciences. 2013;2(5):100-03.

7. Shankar, et al. A fixed removable partial denture treatment for severe ridge defect - A case report. Int J Dent Case Reports. 2011;1 (2):112-18.

8. Andrews James A, Biggs Walter F. The Andrews Barand-Sleeve-Retained Bridge: A clinical report. Dentistry today. 1999;18(4):94-6. 98-99. [PubMed]

9. The glossary of prosthodontic terms 8 . The Academy of Prosthodontics. The Journal of Prosthetic Dentistry. 2005;94(1):10-92. [PubMed]

10. Sadig WM. Bone anchored Andrews bar system. A prosthodontic alternative. Cairo Dent J. 1995;11(1):11-5.

11. Stein RS. Pontic-residual ridge relationship: a research report. J Pros Dent. 1966;16(2):251-85. [PubMed]

12. Nallaswamy Textbook of Prosthodontics. (2nd edition):606-609.

13. Salinas TJ, Finger IM, Thaler JJ 2nd, Clark RS. Sparkerosion implant supported overdentures: Clinical and laboratory techniques. Implant Dent. 1992;1(4):246-51. [PubMed] 